\title{
Видове интервенции при лечение на хъркане и обструктивна сънна апнея
}

\author{
Пл. Недев 1 , Г. Бояджиев², М. Милков \\ ${ }^{1}$ Клиника по УНГ-болести при МБАЛ "Св. Марина" - Варна, \\ Катедра по неврохирургия, оториноларингология и офталмология при \\ МУ "Проф. д-р П. Стоянов" - Варна \\ 2Министерство на вьтрешните работи, \\ Медицински институт - Клиника по УНГ-болести \\ 3Специализирана УНГ-клиника "Св. Петка" - Варна
}

\begin{abstract}
There are many approaches for snoring and sleep apnea syndrome management: some of the approaches are conservative and some of them are related to surgical treatment. The aim of this study is to propose literature review and an assessment of the different surgical methods of snoring and SAS management. Until now there is not a universal surgical procedure that could be accepted as the most effective one.
\end{abstract}

Keywods: Snoring, Sleep apnea syndrome, Uvulopalatoplasty

\section{Резюме}

За лечението на хъркането и синдрома на обструктивна сънна апнея са предтожени многобройни способи, които могаг да се обединят в две големи групи: консервативни и оперативни. Целта на настоящия труд е да се направи литературен обзор и да се оценят прилаганите хирургични способи. Голямото им разнообразие свидетелства, че и до днес няма една хирургична техника, която да е универсална и най-ефективна.

Ключови думи: хъркане, слип апнея синдром, увулопалатопластика
1 а разстройствата на съня започна интензивно да се пише и да се съобщава през последните 10-15 години. Разстройствата на съня обаче се познават от дълбока древност, за което свидетелстват древногръцки и латински текстове. Намираме данни, че добре се е познавала връзката между тежкото хъркане и паузите в дишането и се е намирала като болест, която се отразява на социалния живот.

Според някои изследователи началото на сънната медицина се поставя със статията на Terry Young в New England Journal of Medicine през 1993 год., докато за други тя започва с откритието на Colin Sullivan за continuous positive airway pressure therapy през 1981 г., след което започна бързо индустриално развитие на продукта. Понятието OSAS (obstructive sleep apnea syndrome) е въведено от Christian Guilleminault през 70-те години на 20. век. Hans Berger oт Freiburg in Germany открива, че EEG по време на сьн значително се различава от тази, проведена в будно състояние, и само избухването на Втората световна война попречва той да спечели Нобелова награда за това. През 1959 г. Jouvet et al. публикуват данни за REM фазата на съня. У нас през 1996 г. бе поставено началото на хирургичното лечение на хъркането и слип апнея синдром с дисертацията на Илия Йовчев.

Иначе всички знаем за прекрасното обяснение от Charles Dickens през 1836 г. в Pickwick papers за малкия дебел Джо, който заспивал в право положение, 
дори когато разговаряли с него. В негова чест през 1959 г. Burwell, Robin et al. въвеждат понятието Pickwick синдром, понятие, което все още се използва широко и в наши дни, колкото и да е ограничено по обхват. Подобни литературни образи са Asterix и Obelix от Uderzои Goscinny.

Така че проявите на сънната апнея са се познавали от дълбока древност, но интензивното проучване на проблема със съвременните средства на медицината е в последните 15-20 години.

Може би заради голямата сложност и комплексност на проблема и недобре изяснената патофизиология на синдрома на сънната апнея за лечението са предложени многобройни способи, които могат да се обединят в две големи групи: консервативни и оперативни. Целта на настоящия труд е обзор на най-често прилаганите хирургични способи.

Има много данни, че и в древността са се извършвали операции на увулата и мекото небце. Аристотел и Хипократ през 4 век пр. Хр. са посочвали увулата за причина за възпаления и за задушаване. Византийски лекари са препоръчвали увулектомия при риск от задушаване. И в наши дни традиционната увулектомия се извършва в Средния изток обикновено от бръснари, народни лечители и др., като нерядко се получават тежки усложнения, инфекции, тежки кръвоизливи, ринолалия аперта и др. При едно проучване в Нигерия от Prual A., Gamatie Y., Djakounda M. et al. (1994) $17.2 \%$ от 61 деца са починали в болницата от усложнения. Въпреки това увулектомията продължава да се прилага широко в Танзания, Чад, Мароко, Камерун и др.

\section{Увулопалатопластика}

През 1964 год. японският хирург Ikematsu описва увулопалатопластика. През 1981 год. с малка модификация тази оперативна интервенция е разпространена и в САЩ от Fujita.

Идеята на оперативната интервенция е да освободи повече пространство за протичане на въздуха и да редуцира вибриращите части. При тази техника на пациента се прави тонзилектомия под обща анестезия, след което се отстраняват увулата, част от мекото небце и тонзиларните плики. След това се извършва зашиване на свободните краища.

Ранните резултати показали, че хъркането се редуцира от 75 до $100 \%$ от случаите. Friedman et al (2002) съобщават за $80 \%$ успех в следващите 6 месеца. По-късно, при проследяване на същите пациенти се установило, че процентьт спаднал от 46 до $73 \%$. Не е установена причината за това намаление. Няма и установен стандарт за измерване интензитета на хъркането. Почти всички изследвания се базират на показанията на партньоpa, с който спи. Измерването с различни скали още повече усложнява прецизирането. Друг проблем е какво се приема за успех - дали редуцирането на хъркането, или пълното му премахване. При още по-дълго проследяване на пациентите се установява, че процентът на успех спада още повече - до $46 \%$ (Levin et al., 1994).

Сериозните усложнения са в 2 до $11 \%$ от случаите от постоперативна обструкция, която резултира в 1\% смъртност и следоперативно кървене от 2 до $5 \%$ от случаите. Освен това в $5 \%$ от случаите е имало трудна инкубация. Всички проучвания съобщават за значителна постоперативна болка (Katsantonidids et al., 1990; Croft et al., 1990). B дългогодишен план усложненията са от съхнене на гърлото и велофарингеална недостатъчност. Правените проучвания по въпроса показват значителен процент на оплаквания от постоянна или интермитентна регургитация в първата година след операцията - 10 до 24\% (Haavisto et al., 1994; Fairbanks et al., 1990). Оплакванията от постоянна сухота в назофаринкса са при $31 \%$ от случаите. Други усложнения, на които се обръща по-малко внимание, са загубата на вкус, назофарингеална стеноза, промяната в тембъра на гласа. Не е маловажно да се добави, че UPPP е една скъпа оперативна интервенция - цената, заедно с проследяване в интензивно отделение, струва средно $10600 \$$

При пациенти със значително стеснение в назофаринкса се препоръчва латерална увулопалатопластика (Cahali, 2003).
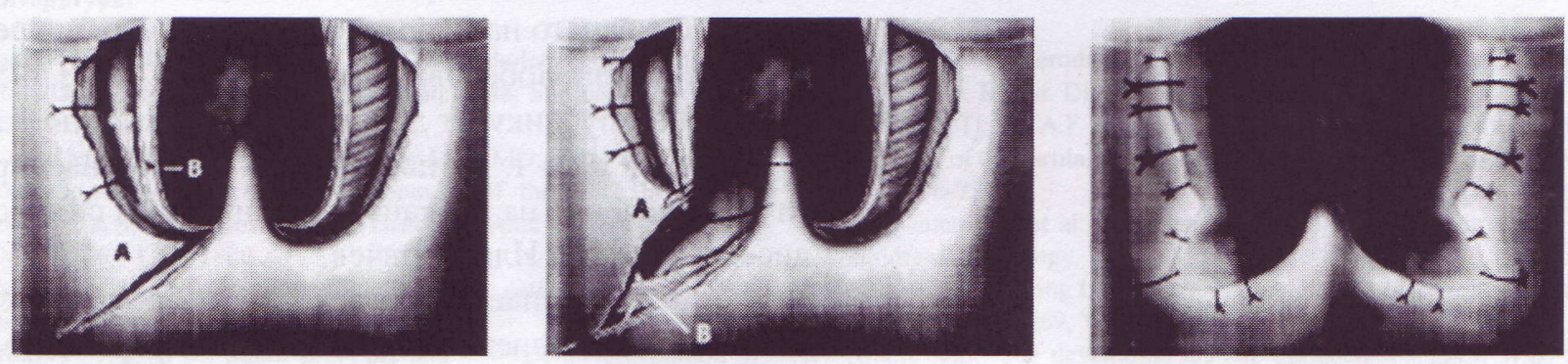

Фигура 1. Латерална увулопалатопластика 
Друга модификация на увулопалатопластиката е оформяне на реверзибилно увулопалатално ламбо (реверзибилна увулопалатопластика). Чрез тази техника значително се намалява постоперативната болка и се намалява опасността от велофарингеална недостатъчност и назофарингеална стеноза.

Тази оперативна интервенция също се извършва под обща анестезия. Удобна е затова, че ако при пациента се забележат признаци за велофалингеална недостатъчност или промяна в гласа, още преди да зарастне ламбото, могат да се свалят сутурите и раната да зарастне вторично при близко до първоначалното положение. Дава много малко усложнения, но неудобството ѝ e, че изисква значително повече време за извършването.

\section{Лазерна увулопалатопластика}

През 1986 год. френският хирург Кататі използва $\mathrm{CO}_{2}$ лазер, за да извърши лазерна вапоризация на палатофаринкса. Това е подобно на UPPP, но в случая тонзилите не се отстраняват и най-често се изпълнява под местна анестезия. Самият Kamami съобщава за успех на интервенцията 97\%. Coleman разпространява тази оперативна интервенция в САЩ през 1992 год. с международно приетото име Laser Assisted Uvulopalatoplasty -LAUP.
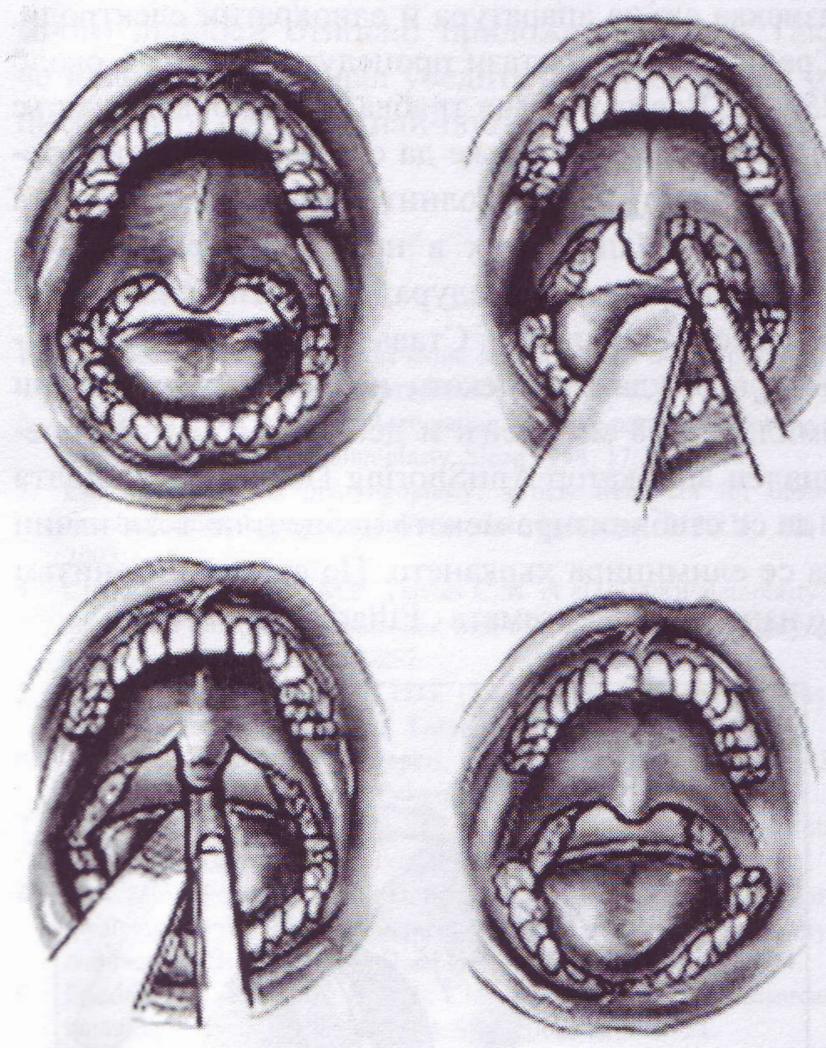

Фигура 2. Лазерна увулопалатопластика
Описаната процедура се препоръчва да се повтори след 4 до 6 седмици. Клиничният резултат е намаление в 70 до $97 \%$ на хъркането. Има две сериозни клинични проучвания, които сравняват LAUP с UPPP (Maw J. et al., 1997; Clarke RW et al., 1998), който не отчита големи разлики в непосредствено проследеното подобрение. Самият Катаmi казва, че при някои пациенти хъркането се възвръща, но по-много по-малко безпокоящо.

Лазерната увулопалатопластика е значително помалко инвазивна процедура. Резекцията на мекото небце е много по-малка, а освен това тонзилите не се отстраняват. Освен това изпълнението на оперативната интервенция се изпълнява под местна анестезия. Това рефлектира в по-малкото следоперативни усложнения, особено кървенето и следоперативната обструкция на въздухоносните пътища. По-малко са и наблюдаваните промяна на гласа и велофарингеалната недостатъчност. В едно голямо проучване на Walker and Gopalsami (1996) са проследени 275 пациенти, на които са били направени 754 процедури. Усложненията са: $1.3 \%$ постоперативно кървене, $0.5 \%$ са имали локална инфекция, $0.5 \%$ са имали временна велофарингеална недостатъчност и $0.3 \%$ са имали временна загуба на вкуса. Не са наблюдавани случаи на смърт, назофарингеална стеноза, промяна в гласа и постоперативна обструкция.

При сравняване на следоперативната болка не се отбелязват някакви големи разлики. Обикновено болката е най-силна между 3 и 9 ден и напълно изчезва след 2 седмици. Това има значение заради това, че за разлика от UPPP, LAUP-та се изпълнява от два до 4 пъти, макар и броят на процедурите да варира.

Разбира се, LAUP има и своите противници. През 1996 Layretano et al. съобщават, че OSAS ce е влошила при някои пациенти, претърпели LAUP. Bce пак трябва да се уточни, че нелекуваната LAUP и с хронично прогресиращ ход и със или без LAUP е възможно пациентът да се влоши. Засега от American Sleep Disorders Association не препоръчват LAUP като средство за лечение на хъркането и OSAS.

По същото време, когато Кататі описва своята техника, шведският хирург Carenfelt описва подобна техника, като я нарича laser uvulopalatplasty (LUPP). Той пак използва $\mathrm{CO}_{2}$ лазер да резицира тъканите на мекото небце, изпълнява я на един етап, но тази процедура не получава такова широко разпространение. 
Други вариации на тази оперативна техника са използване на $\mathrm{Nd}$ :YAG лазер, изпълнението ѝ чрез обикновен каутер, като разликата е само в използването на различни режещи инструменти, за да се изпълни една и съца процедура.

Трябва да се отбележи и фактът, че средната цена на процедурата в САЩ е между 1500 и $2000 \$$.

В стремежа да се избегнат неблагополучията на цитираните две оперативни техники са въведени по-малко инвазивни оперативни техники, „втвърдявацц““ мекото небце. През 1993 год. Ellis et al. демонстрират чрез механичен модел, че при втвърдяване на мекото небце се намаляват вибрираците му движения и това редуцира хъркането. Те препоръчват да се използва $\mathrm{Nd}: \mathrm{YAG}$ лазер, за да се изреже надлъжна ивица от мекото небце, оставяйки увулата и мекото небце интактни. Проследени са 16 пациенти, като резултатите се съизмерими с тези от UPPP, но при минимални усложнения.

Ingram et al. (1996) изполгзва $\mathrm{CO}_{2}$ лгазер и ампутира увулата. Clarke et al. (1998) използват електрокаутер и изследват 62 пациенти, като не намират разлики в резултатите при тази процедура, LAUP и UPPP. IІостоперативната болка е била подобна при трите процедури.

Модификация на тази оперативна интервенция e cautery-assisted palatal stiffering operation (CAPSO), въведена от Mair et al. (1996). ІПроследени са 206 пациенти, като се съобщава успех при $92 \%$ от случаите, който спада до 72\% към 12-тия месец. Не се наблюдавани усложнения по време на операцията. Следоперативно при 15 от случаите ималю кървене, при $1 \%$ е ималю временна велофарингеална недостъчност и в сыция процент ксеростомия. Следоперативните болки са били най-силни между 3-тия и 10-тия ден.

Тези оперативни интервенции имат сходни резултати с далеч по-инвазивните LAUP и UPPP. IToмалката им инвазивност допринася за получаването на по-малки следоперативни усложнения. Не е маловажно и това, че те се изпълняват под местна анестезия. Ако се използва и обикновен електрокаутер, се спестяват средства за закупуването на скъпа апаратура. Средната цена на тази оперативна интервенция в САЩ е около $150 \$$.

\section{Радиочестотна хирургия}

IІръв Powell et al. (1997) въвеждат процедура радиофреквентна аблация или сомнопластика.

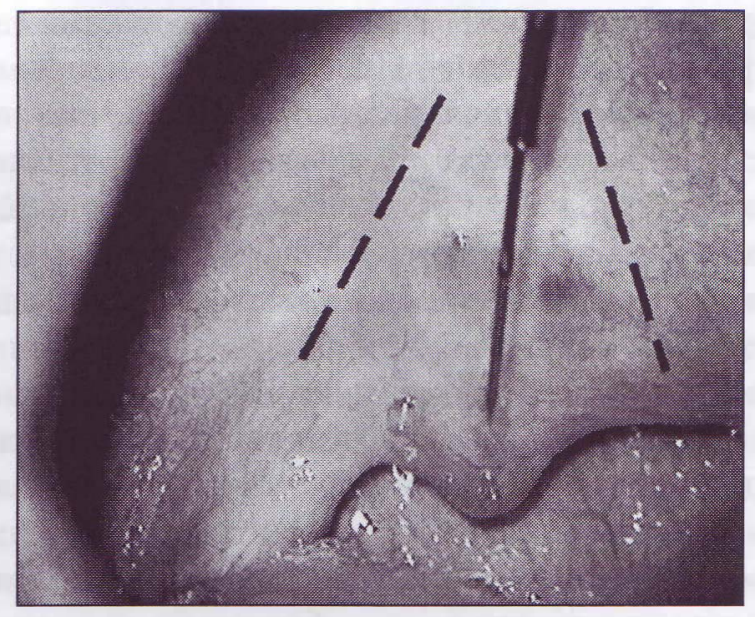

Фигура 3. Местоположение на работния електрод

ІПри проследени 16 пациенти се съобщава за успех в $77 \%$ от случаите. Не се наблюдават сериозни усложнения. Най-често се получава следоперативна некроза на палаталната лигавица на 2 до 4 ден. И тази процедура се изгълнява под местна анестезия. Неудобството е в това, че тази процедури трябва да се повторят. Изисква се и внимание работната игла да се въвежда в мускулите на мекото небце, заццото субмукозното въвеждане ще доведе до гостоперативни ерозии на лигавицата. Процедурата се оскыява от това, че се изисква скъпа апаратура и еднократни електроди. Средната цена на тази процедура в САЩ е около 2500 \$. Все пак обаче трябва да се добави, че със същата апаратура може да се извърши радиофреквентна хирургия на долните носни конхи и базата на езика. Напоследък в практиката се въвежда друга елегантна процедура, сыцо изгълняваща се под местна анестезия. Става дума за вътремускулното въвеждане в мекото небце на полиестерни имплганти 18 мм дълги и дебели 1,5 мм със специален апликатор AntiSnoring Device ASD. ІЦелта е да се стабилизира мекото небце и по този начин да се елиминира хъркането. По съция механизъм се изголзва и системата „Pillar“.

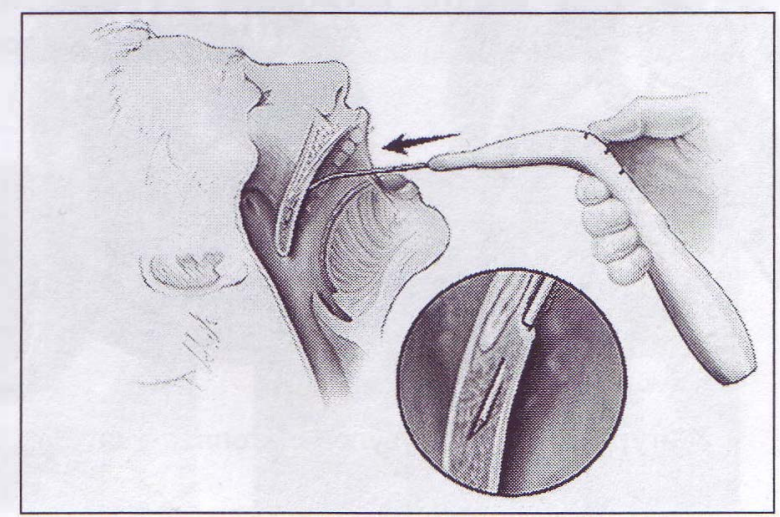

Фигура 4. Система „Pillar" 
Проведените две големи клинични проучвания в Европа, обхващащи 106 човека, доказват, че в повечето случаи хъркането е намаляло или изчезнало съвсем. Не са наблюдавани съществени усложнения, освен понякога частична екструзия на имплантата, налаща цялостното му изваждане.

Няколко фирми използват радиочестотната термотерапия при хабитуално хъркане: „Ellman“, „Sutter“, „Olympus-Cellon“.

Коблацията е друг метод, чрез който се въздейства на мекото небце.

\section{Дискусия}

Всяка от тези процедури има своето място при лечението на хъркането. UPPP има място при пациенти с големи тонзили. LAUP - при пациенти с хипертрофирали задни тонзиларни плики. Радиофреквентната хирургия привлича с това, че под местна анестезия могат да бъдат бързо извършени няколко оперативни интервенции. Освен това тя е и по-консервативна процедура, което е уместно да се приложи като първоначално лечение. При неуспех на следващ етап биха могли да се приложат други оперативни интервенции, коригиращи другите нива на фарингеална обструкция. Въпреки многото методи за обективна оценка на хъркането, методите не са стандартизирани. И има много въпроси относно приложението им. Така че никой още не е дал убедителен отговор кой от цитираните методи е най-добър.

\section{Книгопис:}

1. Йовчев Ил. Хирургично лечение на хъркането и обструктивната слип апнея синдром. Дисертация. София 1996 г.

2. American Sleep Disorders Association. Practice parameters for the use of laser-assisted uvulopalatoplasty. Sleep 1994; 17: 744-748.

3. CahaliMB. Lateral pharyngoplasty: a new treatment for obstructivesleepapnea hypopneasyndrome. Laryngoscope. 113(11): 1961-8, 2003.

4. Clarke R.W., Yardley M.P., Davies C.M. et al. (1998)Palatoplasty for snoring: a randomised controlled trial of three methods. Otolaryngol. Head Neck Surg. 119, 288-292.

5. Croft C. \& Golding-Wood D.G. (1990) Uses and complications of uvulopalatopharyngoplasty. J. Laryngol. Otol. 104, 871-875.

6. Dickens C. The Pickwick Papers. Penguin Classics.Reprint of 18361837 edition. London, UK: Penguin Books; 1986.

7. Ellis P.D.M. (1994) Laser palatoplasty for snoring due to palatal flutter: a further report. Clin. Otolaryngol. 19, 350-351.

8. Finkelstein Y, Stein G, Ophir D, Berger R, Berger G. Laser-assisted uvulopalatoplasty for the management of obstructive sleep apnea:, myths and facts. Arch Otolaryngol Head Neck Surg 2002; 128: 429-434.

9. Friedman M, IbrahimH, Bass L. Clinical staging for sleep-disordered breathing. OtolaryngolHead Neck Surg 2002; 127: 13-21.

10. Grantved A.M. \& Karup P. Complaints and satisfaction after uvulopalatopharyngoplasty. Act. Otolaryngol. (2000) 543(Suppl.), 190-192.

11. Guilleminault C, Dement W. 235 cases of excessive daytime sleepiness. Diagnosis and tentative classification. J Neurol Sci 1977; 31: 13-27.
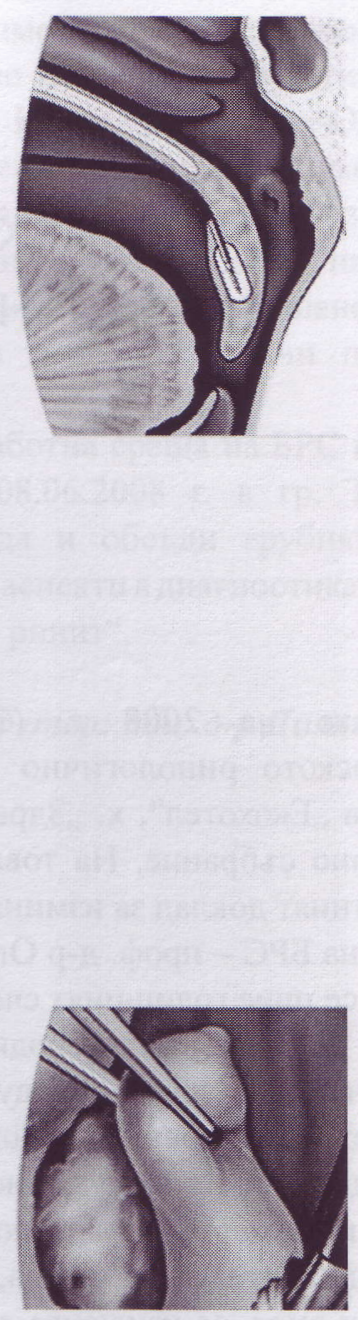

Фиг. 5. Метод на коблация

12. Haavisto L. \& Suonpaa J. (1994) Complications of uvulopalatopharyngoplasty. Clin. Otolaryngol. 19, 243-247.

13. Hagert B., Wikblad K., Odvist L. et al. (2000) Side effects after surgical treatment of snoring. ORL J. Otorhinolaryngol. Relat. Spec. 62, 76-80

14. Kamami Y. Laser $\mathrm{CO}_{2}$ for snoring: preliminary results. Acta Otorhinolar- yngol Belg 1990; 44: 451-456.

15. Kamami YV. Outpatient treatment of sleep apnea syndrome with $\mathrm{CO} 2$ - laser: laser-assisted UPPP. J Otolaryngol 1994; 23: 395-398.

16. Kamami YV. Outpatient treatment of snoring with $\mathrm{CO} 2$ laser: laserassisted UPPP. J Otolaryngol 1994; 23: 391-394.

17. Krespi YP, Pearlman SJ, Keidar A. Laser-assisted uvulapalatoplasty for snoring. J Otolaryngol 1994; 23: 328-334.

18. Osman E.Z., Osborne J.E., Hill P.D. et al. Uvulopalatopharyngoplasty versus laser palatoplasty for the treatment of snoring: an objective randomised clinical trial. Clin. Otolaryngol. (2000) 25, 305-310.

19. Thomas S., Kühnel G., HeinW. Hohenhorst, J. T. Maurer. Soft palate implants: a new option for treating habitual snoring : Eur Arch Otorhinolaryngol (2005) 262: 277-280.

20. Милков М., И. Ценев, Д. Марев, П. Недев, Ц. Тончев. Критичен анализ на биполярна радиочестотна термотерапия използване за редукция на мекото небце и носните конхи при хабитуално хъркане. Международен бюлетин по оториноларингология, бр. 1, 2008, 24-30. 